\title{
SER OU NÃo SER Judeu: SubVERSÃo de ESTEREÓTIPOS RACIAIS EM $O$ MERCADOR DE VENEZA DE SHAKESPEARE
}

\author{
To Be Or Not To Be A Jew: Subversion of Racial \\ Stereotypes In Shakespeare's The Merchant of Venice
}

\author{
Anna Stegh Camati*
}

"Quem é o mercador? Quem é o judeu?" William Shakespeare. O mercador de Veneza

Os ataques terroristas de grupos extremistas, injustificáveis em si mesmos, porém explicáveis em termos de conjuntura política internacional, conduziram muitos pensadores da atualidade a debruçar-se sobre a questão da violência e a investigar os limites e o significado da ideia da (in)tolerância. Lamentavelmente, testemunhamos, nos dias de hoje, o reaparecimento de uma problemática que nos faz lembrar todo um passado de perseguições e atrocidades conduzidas em nome da defesa da superioridade de uma raça e/ou cultura sobre as outras. O problema das diferenças entre grupos étnicos, nações e crenças religiosas voltou a ocupar o centro das discussões sobre a natureza das instituições políticas democráticas ${ }^{1}$ e sobre o significado das relações internacionais entre povos de diversas etnias e culturas.

${ }^{1}$ De 08 de outubro a 07 de novembro de 2002, a violência e a intolerância foram os temas principais de um ciclo de conferências e debates no SESC DA ESQUINA de Curitiba/PR, intitulado Civilização e Barbárie, sob a curadoria de Adauto Novaes. 
No ensaio intitulado "O eu, o outro e a intolerância", Françoise Héritier, com base nos escritos de Jacques Le Goff, comenta que, paradoxalmente, criou-se no século XIII, tempo das catedrais e da grande escolástica,

[...] uma sociedade fundada na rejeição e exclusão dos heréticos, dos leprosos, dos judeus e dos homossexuais. Essa sociedade em pleno desenvolvimento combatia tudo que pudesse ameaçar seu novo nível de prosperidade. $\mathrm{E}$ o fez a partir de concepções muito fortes sobre o sangue, sua pureza e sua unicidade. Heréticos, leprosos, judeus e homossexuais foram considerados 'impuros'. (HÉRITIER, 2000, p. 24)

Ser judeu, por exemplo, tem sido entendido não em termos de práticas e crenças religiosas, mas no contexto da identificação racial e étnica. A pesquisadora argumenta que é na referência aos fatores psicológicos e biológicos que se encontra o máximo do impulso primitivo para rejeitar o outro. Nossa vigilância deve ficar imediatamente alerta, sempre que as noções de impureza e de purificação voltarem a interferir, como ocorreu recentemente, durante o século XIX, quando essas questões novamente ocuparam o centro dos debates científicos que serviram de base, no século seguinte, para as acepções de intolerância e megalomania de Hitler.

Em outro ensaio intitulado "A intolerância institucional; origem e instauração de um sistema sempre dissimulado", Italo Mereu argumenta que a política da intolerância é responsável pelo fascismo, comunismo, nazismo e todos os outros "ismos" dos totalitarismos do século XX. Assevera que a discriminação racial e a intolerância se tornam institucionalizadas por meio de determinações legais que são justificadas por duas projeções ideológicas diferentes - a violência justa e a violência injusta:

A violência justa é a que é empregada por todos aqueles que estão à frente de uma instituição dominante contra qualquer tipo de oposição. Ela é dignificada e dignificante, santificante, merecedora de aplausos e bênçãos. O quadro de Vassari, pintor oficial do século XVI, que representa o massacre dos huguenotes da França, na noite de São Bartolomeu, em 24 de agosto de 1572, é o símbolo da violência justa. O mais importante teórico desse tipo de violência é Santo Agostinho. A violência injusta é a que é empregada pelos heréticos contra a instituição ou contra seus fiéis. É uma violência monstruosa, sacrílega, execrável, que deve ser punida com a morte ou com os mais atrozes castigos. Além do mais, a violência legal é representada pela intolerância institucionalizada. Ela se tornou operante por meio de todo um conjunto de leis. Com a bula Licet $a b$ initio de Paulo III, em 1542, é toda a legislação penal da Idade Média que passa a ser adotada. Só a organização é que mudará: será centralizada e vai operar segundo o princípio intolerante: "Extra Ecclesia nulla salus", "fora da Igreja não há salvação". 
Tudo passará a ser organizado em torno das congregações (nossos atuais ministérios). A primeira congregação será a do Santo Ofício, a princípio presidida pelo papa. Encarregar-se-á de controlar o pensamento. Da mesma forma, será organizada uma congregação De propaganda fide (o ministério da propaganda dos regimes totalitários) com o encargo de difundir a "Boa Notícia". (MEREU, 2000, p. 43-44)

A citação acima mostra que a intolerância e a violência eram procedimentos autorizados e legitimados por aqueles que detinham o poder em estados totalitaristas e que as ações arbitrárias ou a violação dos direitos do indivíduo eram procedimentos de rotina, objetivando o controle absoluto.

O século XX, após o término da Guerra Fria e a Queda do Muro de Berlim, alimentou a esperança de que o racismo estivesse morto e erradicado para sempre. A geração que viveu e testemunhou o espetáculo de horror dos campos de concentração da Segunda Guerra Mundial acreditou que nunca mais coisa semelhante fosse se repetir. No entanto, nos dias de hoje, multiplicam-se uma série de evidências que comprovam haver um recrudescimento estúpido do fanatismo racista mundo afora. Nos quatro cantos do mundo, sob égides e bandeiras diversas, a insanidade racista tem crescido. Em nome de Deus, da nação, da raça e de outros fanatismos, desencadearam-se novos ódios e discriminações, assassinatos em massa, atentados e guerras. Os ideais deturpados do nacional-socialismo continuam seduzindo jovens do mundo inteiro e manifestações neonazistas são comuns nos EUA e na Europa.

A capital paranaense, elogiada mundialmente pela qualidade de vida que proporciona aos seus moradores, foi palco, poucos anos atrás, de lamentáveis manifestações de intolerância e violência contra negros e homossexuais no Largo da Ordem, centro histórico da cidade. Eles foram vítimas de agressões físicas praticadas por jovens que imitam o estilo dos neonazistas no que diz respeito às atitudes, ao vestuário e aos símbolos. A imprensa noticiou a ocorrência de cinco casos e, além disso, panfletos e cartazes racistas também foram espalhados no mesmo local. Em uma matéria publicada em 13 de outubro de 2005, na Gazeta do Povo ${ }^{2}$, intitulada "Os males do preconceito e da discriminação", René Ariel Dotti, ensaísta e membro da Academia Paranaense de Letras Jurídicas, argumenta que essas formas de discriminação, que revelam "componentes morais e materiais do apartheid", são "uma reencarnação da violência física e moral registrada pelas mais variadas expressões da história moderna e antiga”. Relata o jurista:

Em outras matérias publicadas na Gazeta do Povo, em 06 e 08 de novembro de 2005, foi noticiado que existem três subgrupos dos Skinheads em Curitiba, que proliferaram nos subterrâneos da cidade há pelo menos dez anos e que, finalmente, vários componentes foram presos e indiciados. 
CAMATI, A. S. SER ou NÃo SER JUdeU...

Representantes dos movimentos da consciência negra e dos direitos dos homossexuais entendem que a causa primária desses atentados é identificável por dois fatos; o sistema de cotas que a Universidade Federal do Paraná está proporcionando para o ingresso de estudantes e a publicidade que os meios de comunicação têm dado às manifestações e atitudes de núcleos sociais que defendem o direito de opção sexual. (DOTTI, 2005, p. 10)

O jurista faz um veemente apelo de repúdio a esses episódios e argumenta que a sociedade precisa reagir contra essas infelizes ocorrências. Considera o acontecido uma afronta à Constituição do Brasil que recomenda a construção de uma sociedade livre, justa e solidária, e à tradição de convivência pacífica entre as pessoas que vivem no Paraná de todas as gentes. No mesmo artigo também relata um caso de antissemitismo recente no Brasil:

O tema do racismo, denunciado pelas vítimas e pela imprensa, foi há pouco tempo objeto de notável julgamento pelo Supremo Tribunal Federal, que manteve a condenação do editor gaúcho Siegfried Ellwander, responsável pela publicação de livros de conteúdo nazista e de incitamento contra judeus. Na oportunidade, o ex-ministro da Justiça e professor titular da Universidade de São Paulo, Miguel Reale Júnior, emitiu parecer sustentando que o termo racismo é próprio de um tipo de comportamento político e social de restrição ou exclusão de um determinado grupo de pessoas, identificado não só por pertencer a uma raça - o que se revela cientificamente impossível de fixar - mas tendo em vista características culturais permanentes. Trata-se, antes, de uma estrutura mental que considera os outros diversos, não se lhes atribuindo a possibilidade de estar entre nós, de gozar dos mesmos direitos, o que constitui uma expulsão continuada do outro. E constitui, segundo o filósofo francês, Alain Davis 'uma punição maior que a morte'. (DOTTI, 2005, p. 10)

Essa "expulsão continuada do outro", à qual o jurista se refere, também pode ser considerada a causa da onda de violência e tumulto que atinge os bairros periféricos de Paris e de várias outras cidades francesas. Evidentemente, as manifestações e os atos de vandalismo expressam o descontentamento dos imigrantes africanos e do Leste Europeu com a política social de abandono e exclusão absoluta. As revoltas são o meio de expressão da insatisfação geral das minorias marginalizadas ${ }^{3}$.

3 Em sua crônica intitulada "Fora isso...", Luís Fernando VERÍsSIMO, em 13.11.2005, faz um comentário irônico sobre a pseudointegração de muçulmanos e outras minorias na sociedade francesa que, na verdade, continua sendo uma relação entre colonialistas e colonizados: "Fora a revolução latente nos seus arredores, Paris continua a mesma festa, e o fato de você poder dizer isso sem parecer um pateta ou um insensível é parte do problema. Quem visita Paris geralmente nem fica sabendo que existem os banlieus, como um cinturão de desespero e mágoas em volta da cidade, ou imagina o papel do racismo 
Diante dessas ressurgências de preconceitos e discriminações, verifica-se a atualidade da peça $O$ mercador de Veneza, na qual Shakespeare mostra que as escolhas morais e éticas que fazemos são determinadas pelo Zeitgeist ou espírito da época em que vivemos. No programa do espetáculo, levado à cena em 1996, o encenador Amir Haddad, faz considerações críticas sobre a espantosa lucidez e modernidade de Shakespeare, visto que em $O$ mercador de Veneza, o dramaturgo tece reflexões sobre os males da intolerância e preconceito que agitaram o seu tempo. Em seu contundente texto de introdução ao espetáculo, o diretor faz um paralelo irônico entre os primórdios da modernidade e o nosso tempo:

\begin{abstract}
Ali onde tudo começou. Uma nova ética e uma nova moral irrompendo e abrindo caminho através de séculos na formação de um universo que parece querer engolir o planeta, mais do que conduzir. E depois, quando resolvida a questão da 'justiça', o judeu, de vítima, se transforma em réu, os cristãos do mesmo barco irão demonstrar a grandiosidade de seus sentimentos e a beleza da idéia do perdão: o judeu que não quis perdoar será, por artifício da justiça que protege os semelhantes, condenado à morte se seus acusadores não forem generosos com ele. E eles o serão. $O$ perdão transforma os homens em Deus! Ensinarão ao judeu vilão, vingativo e usurário a beleza do perdão. Sua vida será poupada! Mas seus bens serão confiscados, metade em vida, para o estado (Veneza), e a outra metade estará desde já garantida para a sua filha Jéssica (que renunciou a sua fé) e seu marido cristão. Ao judeu resta apenas o usufruto desta parte de seu patrimônio. $E A$ ABJURAÇÃO DE SUA FÉ. Será igual, portanto, a qualquer um deles, cristãos. Milagre conseguido através da grandeza do perdão! Um igual mesmo que diferente. Não há neste mundo lugar para um estranho. E com a abjuração poderão todos partir para os verdes campos de Belmonte (menos o judeu), onde irão viver felizes para sempre com a sensação do dever cumprido e do saneamento efetuado. Chegamos ao final. É madrugada, um momento de indefinição anunciando a chegada de um novo dia que não sabemos exatamente como será. Esta hora dúbia da madrugada onde a noite não é mais noite e também não é ainda dia. O que a aurora da modernidade nos trará? A todos nós, turcos, árabes, judeus, brancos, amarelos, negros, africanos, indianos, etc., etc., etc., etc., etc., e tal. (HADDAD, 1996, p. 09, grifo nosso)
\end{abstract}


Em O mercador de Veneza, Shakespeare mostra as constantes tensões decorrentes do ódio racial, religioso e cultural entre o cristão e o judeu, ambos mercenários e usurários, atados em simbiose econômica na Veneza renascentista, centro do capitalismo emergente, onde a peça é ambientada. Na verdade, porém, o objeto da reflexão do dramaturgo é a Londres de sua época, igualmente um grande centro comercial internacional, que também era palco de uma forte onda de antissemitismo. Em evidente paralelo, Shakespeare não só mostra a explosão dos ódios e agressividades de ambos os lados, fruto da intolerância recíproca em suas relações de oposição e dependência, mas também evidencia um processo de desmistificação da ideologia dominante. Trabalha com a técnica épico-distanciadora do deslocamento espaço-temporal, bem antes de Brecht inventá-la. Aliás, sabese que muitos recursos cênicos criados pelo bardo serviram de matriz e fonte de inspiração ao dramaturgo alemão.

Classificada como "comédia sombria", o mercador de Veneza acumula o maior número de releituras, e o judeu Shylock é a personagem mais discutida e reinterpretada. Apesar de participar de apenas cinco das vinte cenas, ele parece dominar a peça inteira. Os críticos afirmam que a temática desse texto remete à forte onda de antissemitismo que varreu Londres em 1593-94. De grande repercussão internacional foi o caso de um judeu português, Roderigo Lopez, que havia atingido uma elevada posição social como médico da Rainha Elisabeth. Ele foi enforcado por ter sido acusado de tomar parte de uma complexa trama política que objetivava o assassinato da soberana. Em função do fanatismo que imperava no momento, a peça $O$ judeu de Malta, de Christopher Marlowe, escrita em 1589, cujo protagonista encarnava todos os vícios que uma visão preconceituosa pudesse conceber, foi remontada pela Companhia do Lorde Almirante, a mais famosa rival do grupo ao qual pertencia Shakespeare. Acredita-se que a Companhia do Lorde Camerlengo teria encomendado um texto sobre essa temática a seu principal autor para concorrer com a casa rival e aumentar os lucros da bilheteria (HELIODORA, 1999, p. 05-11). Porém, diferentemente de Marlowe, Shakespeare evitou o estereótipo ao criar Shylock, plasmando um personagem de extraordinária complexidade que, apesar de apresentar características condenáveis, é um ser humano que sofre e tem motivações compreensíveis para agir da forma que age, sendo ao mesmo tempo vítima de constantes perseguições e carrasco vingativo.

Shakespeare foge da visão maniqueísta, introduzindo na peça uma série de argumentos que mostram as raízes dos conflitos entre o cristão e o judeu. A estigmatização recíproca faz aflorar as agressividades de ambos os lados: temos aí, como nos esclarece Harris Memel-Fote (2000, p. 46) ", "o Outro e o Mesmo como objetos de duas intolerâncias conjuntas, mas

${ }^{4}$ A lógica maniqueísta não reconhece que "o Outro encobre uma interioridade que é da ordem do Mesmo, e, no Mesmo, existe dialeticamente 'um si mesmo como um outro', que o filósofo Paul Ricoeur chama de ipseidade, por oposição à mesmidade" (MEMEL-FOTE, 2000, p. 46). 
diferentes". Para ilustrar suas considerações críticas, o teórico menciona diversos exemplos de discriminação dentro das sociedades contemporâneas - o negro na América do Norte e na África do Sul, o judeu na Alemanha nazista e nos EUA e o tutsi na Ruanda do final do século XX. Relembra que "para excluir os judeus e classificá-los como inimigos, Hitler, em Mein Kampf, representa-os de maneira contraditória: uma 'raça negativa', sem criatividade cultural, um parasita, um 'verme no corpo', uma 'sanguessuga', 'um vampiro', mas também uma raça perigosa, que inventou meios inomináveis para corromper a raça ariana e dominar o mundo: capitalismo, democracia, marxismo e comunismo" (MEMEL-FOTE, 2000, p. 48-49).

Sabe-se que $o$ antissemitismo não se originou e nem findou com Hitler na Segunda Grande Guerra: a discriminação e perseguição dos judeus e de outras minorias étnicas e religiosas são fatos recorrentes, ora endêmicos, ora epidêmicos, que têm sua origem nos primórdios da história da humanidade. Os judeus haviam sido banidos ${ }^{5}$ da Inglaterra em 1290, por Eduardo I, que foi o primeiro regente europeu a realizar uma limpeza étnica em seu estado [Judenrein] (SHAPIRO, 1996, p. 53). Apesar de não haver muitos judeus na Inglaterra de Shakespeare, a sociedade elisabetana, preocupada com as noções emergentes de nacionalidade e raça, nutria profundas inquietações a respeito das questões judaicas, que incluíam inúmeras falácias a respeito das diferenças raciais e culturais dos semitas. o mito do estereótipo físico estava enraizado no imaginário popular: a pele escura, o nariz adunco, o mau cheiro, a indumentária característica e a maneira de andar e de falar. Além de estigmatizados por seus hábitos alimentares, os judeus ainda inspiravam horror pelas ideias preconceituosas difundidas a respeito deles: o mito da não confiabilidade, do espírito vingativo e da criminalidade, como por exemplo, a crença do assassinato ritual de crianças cristãs (SHAPIRO, 1996, p. 33-42).

A consciência racial era uma característica do nacionalismo emergente na Inglaterra e a racionalização dessa questão era uma constante. Paulatinamente o mito do estereótipo judeu, facilmente reconhecível, é subvertido, porque as diferenças raciais e culturais não eram tão óbvias como os ingleses gostariam que fossem. Por fim, instala-se uma verdadeira fobia em relação à miscigenação racial e contaminação do sangue, uma vez que, na realidade, não era fácil identificar um judeu, devido à perda da identidade judaica dos convertidos. A população tinha verdadeiro horror só em pensar de misturar seu sangue com descendentes judeus convertidos, que eram considerados impuros, falsos judeus e/ou cristãos ilegítimos, porque muitos dos que haviam ficado na Inglaterra não se diferenciavam

\footnotetext{
${ }^{5}$ Os judeus foram readmitidos na Inglaterra em 1656, sob a regência de Cromwell.
} 
dos ingleses em relação ao seu comportamento, aparência ou às suas ações. Essa erosão que impossibilitava a diferenciação, paradoxalmente, gerou maiores inquietações entre os ingleses e fez o antissemitismo aflorar com maior virulência - a partir daí a concepção da nacionalidade inglesa passou a depender da exclusão do componente judeu (SHAPIRO, 1996, p. 30-33;16893). Se levarmos em consideração todas essas inquietações da época, a questão levantada por Pórcia, na cena do julgamento, em $O$ mercador de Veneza, quando ela pergunta: "Quem é o mercador? Quem é o judeu?" (SHAKESPEARE, 1999, p. 115), adquire novos contornos.

O mercador de Veneza traz em si uma multiplicidade de discursos dissonantes e uma série de indagações. São justamente esses elementos que marcam a genialidade de Shakespeare: ao não assumir um ponto de vista definido, a peça deixa claro que a reflexão sobre os problemas levantados deve ir além dos conceitos da vítima e do carrasco, do outro e do mesmo. $O$ dramaturgo desconstrói os estereótipos com grande sutileza e usa recursos cômicos para tratar de temas sérios.

O famoso discurso de Shylock, em que o judeu insiste na semelhança dos atributos humanos entre cristãos e judeus e expressa sua revolta com relação à intolerância, introduz a temática da inversão de papéis, que será o leitmotif da peça; a fala de Shylock faz lembrar o quão facilmente se invertem os papéis de carrasco e vítima, fato que realmente acontece no decorrer da peça: o judeu passa de vítima a carrasco e novamente à vítima no final:

Eu sou judeu. Um judeu não tem olhos? Um judeu não tem mãos, órgãos, dimensões, sentidos, afeições, paixões? Não é alimentado pela mesma comida, ferido pelas mesmas armas, sujeito às mesmas doenças, curado pelos mesmos meios, esquentado e regelado pelo mesmo verão e inverno, tal como um cristão? Quando vós nos feris, não sangramos nós? Quando nos divertis, não rimos nós? Quando nos envenenais, não morremos nós? E se nos enganais, não haveremos nós de nos vingar? Se somos como vós em todo o resto, nisto também seremos semelhantes. Se um judeu enganar um cristão, qual é a humildade que encontra? A vingança. Se um cristão enganar um judeu, qual deve ser seu sentimento, segundo o exemplo cristão? A vingança, pois. A vileza que me ensinais eu executo, e, por mais difícil que seja, superarei meus mestres. (SHAKESPEARE, 1999, p. 77-78)

No período entre guerras, houve a proliferação de um grande número de montagens antissemitas que tenderam a cortar a parte final do discurso de Shylock, porque estas palavras remetem à questão da retaliação, à violência que gera violência, ideia malvista nas interpretações racistas da 
peça de Shakespeare. As ressonâncias sinistras dessas palavras adquiriram um significado especial após 11 de setembro de 2001. Hoje, em um mundo de oportunismos, corrupção e falta de ética, as vítimas oprimidas das minorias étnicas decidiram revidar com a destruição dos símbolos de poder dos EUA, disseminando uma onda de terror em vários países que apoiaram a política agressiva de George W. Bush.

No processo de desmistificação da ideologia dominante, Shakespeare, em $O$ mercador de Veneza, aponta o poderio econômico do judeu como uma das causas de sua demonização. No final do Ato IV, Shylock é transformado de reclamante em réu. É ludibriado e todos os seus bens são confiscados. Além de ser obrigado a abjurar sua fé e a abraçar a religião cristã, ainda lhe tiraram a base de seu sustento. Temos aí uma clara indicação de que a discriminação racial e/ou a aniquilação total de grupos étnicos foi e sempre será uma questão de interesses para preservar o poder hegemônico ${ }^{6}$. Como bem observou Peter Sellars, cuja montagem d'O mercador de Veneza estreou no Goodman Theatre em Chicago, em 1994:

Há quatro séculos passados, no momento em que o moderno capitalismo foi inventado, Shakespeare escreveu uma peça que continua sendo a análise mais franca e perspicaz que possuímos das raízes econômicas do racismo. Não por acaso, ele chamou sua obra de $O$ mercador de Veneza. A Veneza de Shakespeare é um centro internacional de comércio, que tem a China, África, as Américas e o mundo árabe como parceiros de negócios. Quando selecionei atores afro-americanos para desempenhar os papéis dos judeus, asiáticos para representar Pórcia e sua corte, e latinos para encarnar os venezianos, acho que consegui tocar no âmago da ferida da América contemporânea; o âmbito da metáfora e da realidade do anti-semitismo foi ampliado para incluir os conflitos paralelos e as questões relacionadas a eles. (apud WORTHEN, 1997, p. 77 , minha tradução).

A ambientação de um filme mais recente, idealizado e dirigido por Michael Radford, é a Veneza de 1596, ano em que a peça foi escrita. O cineasta coloca grande ênfase no tema da exclusão social. Vemos os portões do ghetto sendo trancados com um grande ferrolho no início do filme e, no final, a porta da sinagoga é fechada para servir de índice para a exclusão de Shylock, obrigado a se converter ao cristianismo. Radford nos apresenta

${ }^{6}$ Em um texto intitulado "O respeito à lei - o estado de direito", o advogado Nelson das Neves Brandão afirma que esta cena constitui um exemplo de violação "do estado de direito através de um truque", uma vez que, segundo as leis da época, "o pleito de Shylock era plenamente válido jurídicamente". O truque consiste em exigir que não se derrame sangue: "a lei que reconhece o direito de cortar uma libra de carne, também reconhece, implicitamente, o direito ao sangue, sem o qual, na hipótese, não há carne" (BRANDÃO, 1997, p. 3). 
uma leitura pós-holocausto, inserindo em seu filme indícios que revelam a hipocrisia da sociedade mercantilista cristã, que pune o judeu por ser usurário, mas depende do empréstimo de seu dinheiro para sustentar seus negócios ${ }^{7}$.

Hoje, as sociedades dos países que integram a União Europeia, em evidente paralelo com a sociedade veneziana do início da modernidade em relação aos judeus, também se recusam a reconhecer a cidadania dos imigrantes que representam quinze por cento da força de trabalho dos diversos países em que estão radicados. Esta política faz proliferar a violência. Em $A$ violência em construção, Belini Meurer (2003) relata a situação dos imigrantes que se deslocam de um lugar para outro em busca de trabalho e melhores condições de vida, estabelecendo-se preferencialmente nos países ricos. Argumenta que:

\begin{abstract}
Essas pessoas estrangeiras vivem uma dicotomia perversa. Por um lado são indispensáveis para o barateamento da mão de obra nas regiões mais ricas, assim como são os responsáveis pelos trabalhos indesejáveis; entretanto, são recebidos como perigosos invasores pelos patrícios. Dá-se o início, a partir daí, a toda sorte de discriminação que pode ir desde um simples olhar de reprovação, ao xingamento, a não aceitação em determinados espaços públicos, ou a não contratação para certos trabalhos, ou até mesmo a agressão física. (MEURER, 2003, p. 35)
\end{abstract}

Diversos pensadores do contemporâneo, que tentam construir um pensamento crítico sobre os caminhos do homem no início deste novo milênio, acreditam na necessidade de uma mudança sobre a forma de se pensar a sociedade. Se a Europa não voltar seus olhos com urgência para os problemas de sua população imigrante e não suprimir a odiosa discriminação de caráter étnico e religioso, será palco de um futuro sombrio. Paris e outras metrópoles não estarão livres do ressurgimento de manifestações de protesto ainda mais violentas.

Na época de Shakespeare, os cristãos eram impedidos de emprestar dinheiro a juros devido a uma proibição constante nos evangelhos. O exercício das profissões não era facultado aos judeus, sobrando-lhes poucas áreas para atuar, entre elas a usura. Os judeus, portanto, eram usados pelos cristãos para desempenhar o trabalho considerado sujo. Eram tolerados em Veneza com o exclusivo propósito de impedir os cristãos de cometerem o pecado da usura. Uma atitude paradoxal em relação aos judeus era corrente: por um lado, eram desprezados pela sua origem e raça e, por outro lado, apreciados por sua utilidade econômica (NUTTAL, 1983, p. 288). 


\title{
RESUMO
}

As ressurgências de preconceitos e discriminações no século XXI nos convidam a refletir sobre $O$ mercador de Veneza, cuja problemática continua sendo atual. Nesta peça, Shakespeare revela os mecanismos da lógica maniqueísta, vira os estereótipos de cabeça para baixo e manipula os conceitos das construções culturais com grande sutileza. o dramaturgo toma como objeto de análise e reflexão o ódio racial, religioso e cultural entre o judeu e o cristão, atados em simbiose econômica na Veneza renascentista, centro do capitalismo emergente. Objetiva mostrar que a intolerância recíproca é responsável pela explosão dos ódios e agressividades por parte de ambos em suas relações de oposição e dependência. No processo de desmistificação da ideologia dominante, o bardo aponta o poderio econômico do judeu como uma das causas de sua demonização.

Palavras-chave: Alteridade; Shakespeare; O mercador de Veneza.

\begin{abstract}
The recurrent manifestations of prejudice and discrimination in the $21 \mathrm{st}$ century invite us to reflect on the contemporaneousness of The Merchant of Venice. In this play, Shakespeare reveals the mechanisms of the Manichaean logic, turns stereotypes upside down and cunningly manipulates the concepts of cultural construction. He selects as his object of analysis and reflection the racial, religious and cultural hatred between the Jew and the Christian, tied up in a process of economic symbiosis in the Venice of the early modern period, centre of nascent capitalism, showing that the reason for aggressive impulses exploding on both sides has to do with the reciprocal intolerance which arises from their being tied up in a relation of opposition and dependence. In the process of demystifying the dominant ideology, the bard suggests that the economical power of the Jew is the crux of his demonization.
\end{abstract}

Keywords: Alterity; Shakespeare; The Merchant of Venice. 
CAMATI, A. S. SER ou NÃo SER Judeu...

\section{REFERÊNCIAS}

BRANDÃo, Nelson das Neves. O respeito à lei - o estado de direito. Trabalho apresentado no Curso "Shakespeare, Nosso Contemporâneo", ministrado por Anna S. Camati e Célia A. de Miranda, no Solar do Rosário, Curitiba, 1997, 4p..

DOTTI, René Ariel. Os males do preconceito e da discriminação. Gazeta do Povo, Curitiba, p. 10,13 out. 2005 .

GAZETA DO POVO, Curitiba, 06 e 08 nov. 2005.

HADDAD, Amir. Uma vitória amarga. Rio de Janeiro, 1996. Programa do espetáculo $O$ mercador de Veneza, de William Shakespeare.

HELIODORA, Barbara. Introdução. In: SHAKESPEARE, William. O mercador de Veneza. Tradução de Barbara Heliodora. Rio de Janeiro: Lacerda, 1999.

HÉRITIER, Françoise. O eu, o outro e intolerância. In: BARRET-DUCROCQ, Françoise (Org.). A intolerância: foro internacional sobre a intolerância. Tradução de Eloá Jacobina. Rio de Janeiro: Bertrand Brasil, 2000. p. 24-27.

MEMEL-FOTE, Harris,. O Outro e o Mesmo. In: BARRET-DUCROCQ, Françoise (Org.). A intolerância: foro internacional sobre a intolerância. Tradução de Eloá Jacobina. Rio de Janeiro: Bertrand Brasil, 2000. p. 46-51.

MEREU, Italo. A intolerância institucional. In: BARRET-DUCROCQ, Françoise (Org.). A intolerância: foro internacional sobre a intolerância. Tradução de Eloá Jacobina. Rio de Janeiro: Bertrand Brasil, 2000. p. 42-45.

MEURER, Belini. A violência em construção. Joinville: Catarina de Alexandria, 2003.

NUTTAL, A. D. The Merchant of Venice. In: BLOOM, Harold. (Ed.). William Shakespeare: Comedies and Romances. New York: Chelsea House Publishers, 1986.

RADFORD, Michael. The Merchant of Venice. Sony Pictures Classics, 2004.

SHAKESPEARE, William. O mercador de Veneza. Tradução de Barbara Heliodora. Rio de Janeiro: Lacerda, 1999.

SHAPIRO, James. Shakespeare and the Jews. New York: Columbia University Press, 1996. VERÍSSIMO, Luís. Fernando. Fora isso... Gazeta do Povo, Curitiba, p. 15, 13 nov. 2005.

WORTHEN, W. B. Shakespeare and the Authority of Performance. Cambridge: Cambridge University Press, 1977.

Submetido em: 27/09/2008

Aceito em: 10/08/2009 